\title{
Creating Fun Time in Teaching-Learning Experiences through Teachers' Teamwork, Humor, and Innovative Behavior
}

\author{
Aduni binti Johari \\ Professional Development \& Continuing Education's Department \\ Faculty of Educational Studies, Universiti Putra Malaysia, 43400, Serdang, Malaysia \\ Nor Wahiza binti Abdul Wahat (Corresponding author) \\ Professional Development \& Continuing Education's Department \\ Faculty of Educational Studies, Universiti Putra Malaysia, 43400, Serdang, Malaysia
}

\section{Khairuddin bin Idris}

Professional Development \& Continuing Education's Department

Faculty of Educational Studies, Universiti Putra Malaysia, 43400, Serdang, Malaysia

Received: Oct. 3, 2021 Accepted: Nov. 15, $2021 \quad$ Online published: Nov. 22, 2021

doi:10.5296/ijhrs.v11i4S.19229 URL: https://doi.org/10.5296/ijhrs.v11i4S.19229

\begin{abstract}
According to the Malaysian Ministry of Education's (MOE) national education model, the education system is meant to produce people who are knowledgeable, competent, and able to contribute to the nation's improvement. Educators must demonstrate unique actions to nurture their students seamlessly and systematically, according to the idea. The purpose of this paper is to present an empirical study that looks at the impact of humor and teamwork on teachers' innovative behaviors in Malaysian secondary schools. The goal of this study was to find out how engaged teachers are in innovative behavior (IB) in terms of idea generation (IGEN), idea promotion (IPROM), and idea implementation (IIMPL), as well as to look at the relationship between humor (HUM) and teamwork (TW) and IB (IB). This quantitative study was conducted using a survey of 354 selected respondents. The respondents were selected from 4,319 teachers in two different zones in the state of Selangor by using the stratified random
\end{abstract}


sampling technique. The findings suggest that there is a good level of teachers' engagement in idea generation, and a moderate level of idea promotion and idea implementation behavior. The findings also reveal that humor and teamwork are positively and significantly correlated to innovative behavior. Overall, this study provides a better insight into how humor and teamwork contribute to teachers' innovative behavior.

Keywords: national philosophy, teachers' innovative behavior, humor, teamwork

\section{Introduction}

In May 2020, during the Movement Control Order (MCO), Sabah Education Director, Dr. Mistirine Radin emphasized the importance of teachers in Sabah embracing more creative, innovative, and proactive teaching approaches. Teachers must accept the challenge of having smooth online teaching-learning experiences by further enhancing their teaching skills. An individual's activity in originating, producing, using, promoting, realizing, and altering new ideas to improve task performance is referred to as creative behavior (Konermann, 2012). In the field of education, innovation may aid in the improvement of present teaching methods, resulting in better learning outcomes. When different innovations are incorporated into a standard course of studies, such as leveraging multimedia to present new topics more expressively and applying more effective teaching methods or new mnemonic techniques, students' learning productivity may rise to some level, as Meyer (2014) points out.

The Malaysian government recognizes the need for its educational system to change to address the difficulties of a rapidly changing and uncertain globalized world, as well as the nation's growing aspirations. According to the Malaysia Education Blueprint 2013-2025, the government has emphasized the need of integrating innovations into teaching and learning processes to guarantee that all students are adequately prepared for life and work. To adopt innovations that are adequate and sustainable in education, teachers as the drivers of innovations have been encouraged to be actively involved in facilitating their innovative behaviors through reforms and an improvement in the existing teaching and learning practices (Randi \& Corno, 1997).

Much research has been conducted to investigate teachers' innovative actions. Some academics have found evidence that teachers' innovative conduct has a major impact on their job effectiveness (Balkar, 2015; Xerri \& Brunetto, 2011). Other studies looked at the factors that influence teachers' innovative behavior, either on an individual or organizational level (Binnewies \& Gromer, 2012; Thurlings et al., 2015). However, there is a limited exploration of the research on the interaction between the individual's characteristics and their organizational support, especially the influence of teamwork on innovative behaviors. In addition, there are only a few studies conducted on teachers' innovative behaviors within the context of the Malaysian education system. Hence, the purpose of this study was to fill in the gap in the literature to understand the influence of teamwork and the adoption of innovative behaviors among teachers in Malaysian schools.

Innovative conduct is critical to the teaching profession in the twenty-first century to establish a knowledge society (Bransford et al., 2005). Teachers will need to be more imaginative as new technology and insights about education emerge, allowing society to 
remain competitive in the face of rapid changes in the labor market and work environments. In line with this, the MoE has been taking some measures to encourage the adoption of innovations in teaching and learning practices among teachers in Malaysia. Different training programs have been developed to increase instructors' proficiency in incorporating technology and technology-based practices into all elements of teaching and learning, particularly in learning objectives, lesson preparation, and learning outcome evaluation. Although most teachers understand the importance of innovations in modern education, not all of them are susceptible or receptive to the adoption of innovations in teaching and learning practices. Some teachers are reluctant to innovate, especially when faced with barriers. According to Trapitsyn et al. (2018), the innovative susceptibility of teachers is usually influenced by their motivation to create a good and effective school for students, but the level of their innovation activities can be negatively affected by an excessive workload, the belief that they can still work efficiently using the conventional teaching style, and fear of negative results.

Despite many studies conducted in understanding the significance of innovations in educational institutions, a review of related literature shows that most studies are more concerned with the contributing factors of teachers' innovative behaviors, such as demographic factors (e.g., Liou et al., 2019), individual factors (e.g., Messmann et al., 2018), and organizational factors (e.g., Evers et al., 2011). Little focus has been invested in investigating the extent to which teachers are engaged in innovative behaviors or innovations that have been implemented in teaching and learning practices.

This study was designed to fill these gaps by investigating the extent to which teachers are engaged in idea generation, idea promotion, and idea implementation to adopt innovations within the context of Malaysian secondary schools as well as examining the influence of humor traits and teamwork in enhancing teachers' innovative behaviors. Hence, this study looked at schoolteachers' perceptions of their innovative behaviors, their humor traits, and teamwork among teachers.

The primary goal of this research was to look into the amount of innovative behavior among teachers in Malaysian secondary schools, as well as the impact of teamwork and humor on teachers' innovative behaviors. The goal of this research was to find out how involved teachers were in concept generation, promotion, and implementation. It also aimed to look at the link between humor and the three characteristics of inventive behavior (idea production, idea promotion, and idea implementation). Finally, the study wanted to see if there was a link between the different aspects of teachers' innovative behavior (concept development, idea promotion, etc.).

The results of this study provide teachers with a better insight into how the teamwork factor and human factor may contribute to the development of their innovative behaviors. This would help them to adopt more innovative, creative, fun, enjoyable, hands-on, and flexible forms of teaching that can enhance students' learning and engagement in the classroom to meet the demands of 21 st-century learning. The outcomes of the study are also useful to further explore the relationships between humor and teamwork factors in innovative 
behaviors as suggested by Thurlings et al. (2015) in their research.

\section{Literature Review}

\subsection{Innovative Behaviour}

According to the literature, most studies on innovation followed Janssen's (2003) definition of innovative behavior as a three-stage procedure that includes (a) generating ideas on purpose, (b) promotion of a concept, and (c) enhancing role performance, the group, or the organization, a concept must be realized inside a work role, workgroup, or organization. In the context of educational innovations, teachers' innovative behavior may be defined as executing the innovation by watching, listening to, and adapting ideas, establishing a plan of action, assessing via reflection and evaluation, changing the invention, and recruiting allies (Messmann \& Mulder, 2011).

Janssen (2003) defines teachers' innovative behavior as "the extent to which teachers consciously strive to generate, promote, and realize new ideas by incorporating technology and creativity into all aspects of teaching and learning practices to increase student engagement in the classroom, improve students' learning abilities, and improve students' learning abilities" (based on the discussion above). The level of teachers' adoption of innovative behavior in this study was measured using the self-evaluation survey by assessing their perceptions on three dimensions of innovative work behavior based on the three factors of the second-order model of innovative behavior (Ogbonnaya et al., 2018), which are idea generation, idea promotion, and idea implementation.

\subsection{Humor}

Humor refers to communication that elicits laughter or leads to a feeling of amusement (Warren et al., 2018). It can also be defined as anything that people say or do that is thought to be amusing and causes others to laugh (Vrticka et al., 2013). As a result, humor can be divided into two categories: cognitive (i.e., "the mental processes that go into both creating and recognizing [...]amusing stimuli") and affective (i.e., "the affective reaction in the enjoyment of" that particular stimulus) (Vrticka et al., 2013). Thus, perceiving humor entails both cognition and appreciation processes, and is frequently associated with a sense of delight and satisfaction (Martin \& Ford, 2018).

The use of humor as a pedagogical tool in teaching is not limited to jokes or humorous stories but may also include the use of funny props, puns, short stories, anecdotes, riddles, or cartoons (Weimer, 2013). Many authors suggest that when used appropriately, constructively, and in moderation, pedagogical humor can facilitate the comprehension and retention of learned material (Martin \& Ford, 2018), improve classroom climate, and increase student-teacher rapport (Ahrari et al., 2013), assist teachers in the deliverance of a sensitive content (Noon, 2017), enhance student engagement (Deviney et al., 2013), and encourage a more positive and receptive learning atmosphere (Aboudan, 2009).

The term instructors' humor in this study relates to teachers' perceptions of employing pedagogical humor during class sessions to cause laughter and amusement when interacting with their students and to create a more pleasant, entertaining, and fascinating environment that 
increases learning. The construct was measured based on Askildson (2005) to evaluate the teachers' perceptions of the frequency of humor usage in the classroom, their humor's relevancy to the class subject matter, the extent to which their humor made students feel relaxed in the classroom, the extent to which their humor increased students' interest in learning, the extent to which their humor made them more approachable by students in class, and the extent to which their humor improved students' ability to learn.

\subsection{Teamwork}

"A coordinated action by a group of people, in which each member submits his or her interests and opinions to the unity and efficiency of the group," according to Webster's New World Dictionary. It can also refer to a collaborative effort that enables ordinary individuals to achieve remarkable outcomes (Scarnati, 2001). According to previous research, teamwork in an organization is defined as the collaboration of a group of employees in a team in a cooperative environment with effective and mutual relationships to achieve common team goals and clear purposes through the sharing of knowledge and skills (e.g., Mirkov, 2018).

The concept of teamwork is also based on the social exchange theory, which states that the relationships formed among coworkers stimulate more collaboration and emotional support (Gouldner, 1960). As a result, 'the amount to which employees believe their coworkers are ready and eager to offer them with work-related support to assist them in performing their obligations should be included in the definition of teamwork (Susskind et al., 2003, p. 81). The aid provided goes beyond task-related assistance to include socio-emotional support such as love, caring, and empathy (Nugent \& Abolafia, 2006; Rousseau, Salek, Aubé, \& Morin, 2009). Based on the definition above, the term teamwork in this study is defined as the teachers' perceptions of the collaboration of their colleagues at their school in creating a positive and cooperative environment through effective communication, support and caring relationships, and knowledge/skills sharing to contribute to school success and students' academic performance. The construct was measured based on Ladd and Henry (2000) and the Teacher Collaboration Assessment Survey (TCAS) in terms of three key domains of teamwork: Effective communication, support and caring relationships, and knowledge/skills sharing.

Prior research has shown that educational innovations can include the implementation of a new pedagogic theory, methodological approach, teaching technique, instructional tool, learning process, or institutional structure, which can result in a significant change in teaching and learning practices and a higher quality of learning for students (Serdyukov, 2017).

There have been various previous studies on Malaysian educational innovations and 21 st-century learning. Sumardi et al. (2020) discussed the concept and framework of $21^{\text {st }}$ century learning, instructional and learning theories, new teaching and learning strategies, and educational technology standards that should be used as guidelines to encourage teachers, students, and school administrators to implement innovative teaching and learning in Malaysian schools. Garba et al. (2015) investigated the use of ICT and online resources in Malaysia when it came to using $21^{\text {st }}$ century technology-based teaching-learning methodologies. Their study reveals that despite the facilities provided, the level of technological competence acquired by teachers, and the level of computer and internet usage in teaching were still not up to the desired standard. They also highlighted that many teachers 
faced challenges in integrating technology in their teaching-learning approaches due to the continuous emergence of recent digital technologies. Rusdin (2018) who studied Malaysian teachers' readiness in implementing $21^{\text {st }}$ century learning found that the teachers were eager to implement $21^{\text {st }}$ century learning, but their understanding of $21^{\text {st }}$ century skills was still insufficient to achieve their best teaching practice. Therefore, Rusdin (2018) recommended for teachers be equipped with teaching modules that guide the best hands-on activities related to $21^{\text {st }}$ century learning skills.

Much prior research has used Janssen's (2003) definition of innovative behavior, which includes (a) intentional idea development, (b) idea promotion, and (c) concept realization within a work position, workgroup, or organization to enhance role performance, the group, or the organization. Teachers' innovative behavior, according to Messmann and Mulder (2011), entails observing, listening to, and adapting ideas, developing strategic actions, assessing through reflection and assessment, changing the innovation, and seeking allies.

Concerning the three-stage process involved in innovative behavior provided by Janssen (2003), idea generation in teachers' innovative behavior can be described as teachers' formulation of new ideas in teaching and learning. Idea promotion in teachers' innovative behavior can be described as teachers finding allies like their colleagues or school leaders to gain their support for enabling idea realization (Rami et al., 2018; Messmann \& Mulder, 2011). Meanwhile, idea realization in teachers' innovative behavior can be described as the processes involved in transforming the idea into a prototype, model, or application (e.g., Messmann \& Mulder, 2011).

Amir (2015) conducted a validation study on multidimensional constructs of innovative behavior in the context of organizations in Indonesia using the three-stage process of Janssen's (2000) scale. These three factors of the second-order model of innovative behavior consist of three dimensions: Idea generation, idea promotion, and idea implementation (see Figure 1).

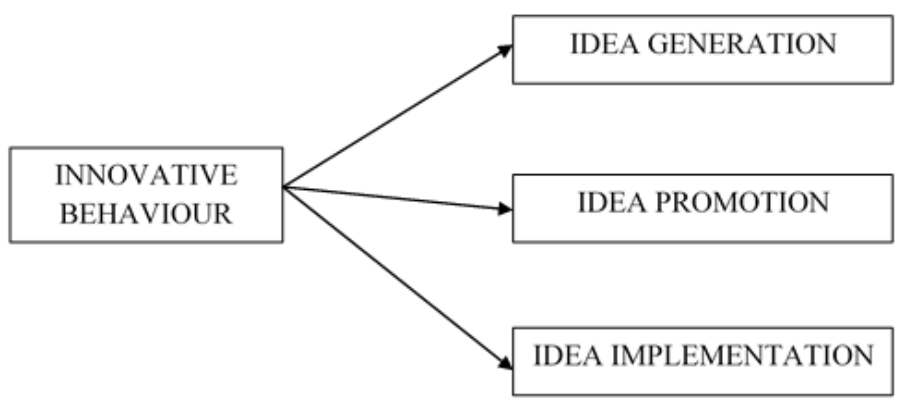

Figure 1. The three factors of the second-order model of innovative behavior (Janssen, 2000)

The idea generation stage, according to this paradigm, entails researching prospects with curiosity (Kleysen \& Street, 2001), which forces one to obtain a new idea from fresh sources. One trait that distinguishes innovators from ordinary employees is their proclivity for collecting and organizing information related to possibilities (Johari et al., 2021). The idea promotion stage involves gaining socio-political support for the generated ideas (Janssen, 2003). It is up to the innovators' persuasion abilities and efforts to secure support from those who have the power or influence to determine the situation for the initiative to move forward 
(Janssen, 2003). Almost all of the skills and processes required for succeeding concept promotion levels are required at the idea implementation stage (Stevenson et al., 2019).

Horng et al. (2005) investigated the factors that influence creative teaching to better understand the relationship between teachers' humor and inventive behavior. They discovered that one of the factors of instructors' classroom creativity is their sense of humor. Yu et al. (2018) add to this theory by stating that adult playfulness has an impact on creative teaching and teachers' inventive conduct. Nguyen (2014) goes on to say that incorporating humor into the classroom might be viewed as a novel technique to assist students to learn more efficiently.

Teamwork is described as a group of individuals working together to achieve a similar objective by sharing information and skills in a cooperative environment with effective and mutual connections (Tarricone \& Luca, 2002). Many firms have teams because teamwork inside or between teams can contribute to organizational success. Teachers' teamwork can be defined as the collaboration of a group of teachers in their schools who are dedicated to the school's success and the academic performance of their students by working effectively together and creating a positive work environment at the school through effective communication, support, and caring relationships.

Teamwork has been linked to inventive conduct in previous research. Increased communication in a cooperative climate and networking among colleagues, according to Horng et al. (2005), may increase the creation of innovative ideas. Successful cooperation also encourages team members to try out new ways of working more efficiently, to seek out best work practices, to solve problems, and to be open to changes, innovations, and creativity (Tarricone \& Luca, 2002).

This study utilized the innovation adoption and theory of diffusion (Rogers, 1995), and social cognitive theory (Bandura, 1977) Rogers' (1995) theory of diffusion explains the profile of innovative adopters (from early adopters to laggards) as well as essential elements that enable adoption. "Diffusion is the process by which an innovation gets disseminated through certain channels among the members of a social system over time," (Rogers, 1995, p. 5). Communication becomes a process where individuals communicate knowledge to reach a mutual understanding in this model of the innovation system. One of the aspects that must be acknowledged when using technology as a teaching tool is the social process, which individuals tend to adopt or reject as a result of dialogues with others (Hall \& Hord, 2001). According to Bandura's social cognitive theory (Bandura, 1977), the social environment can boost an individual's occupational self-efficacy in two ways: by providing positive feedback ('social persuasion') and by allowing them to learn from others ('vicarious experience').

\section{Method}

\subsection{Participants and Procedure}

This research was conducted based on the quantitative approach using the survey method, which permits efficiency of data collection within a specific period of a school session. A self-administered questionnaire was utilized to collect the data for the survey. Teachers could express their thoughts using the standard measurements provided in the questionnaire, and it 
was an acceptable medium that did not take up too much of the teachers' time. Based on Krejcie and Morgan (1970) table, sample size of 354 respondents consisted of national secondary school teachers from five selected secondary schools located in Ampang and Cheras zones in the district of Hulu Langat, Selangor. The schools were selected based on the stratified random sampling method. The total number of secondary school teachers in these areas is 4,319 .

The research instrument of this study was a set of questionnaires, which was structured and organized to serve as the primary source of information on the respondents' perception of innovative behavior (IB), i.e., idea generation (IGEN), idea promotion (IPROM), and idea implementation (IIMPL), humor (HUM), and teamwork among colleagues at school (TW). The data collected were processed using the SPSS version 26.

\section{Results and Discussion}

Reliability analysis was carried out to test the reliability of each construct in this study. By using software, Cronbach's alpha model was used to test the internal consistency of the item scale for the study variables namely IB, HUM, and TW based on the data obtained from the pilot study. The result of reliability analysis for all the variables used in this study is shown in Table 1.

Table 1. Reliability coefficients of study instruments of the pilot study ( $\mathrm{n}=30$ )

\begin{tabular}{cccc}
\hline No. & Instrument & Number of Items & Cronbach's Alpha \\
\hline 1 & Innovative Behavior & 15 & .895 \\
2 & Teamwork & 15 & .954 \\
3 & Humor & 10 & .951 \\
\hline
\end{tabular}

A descriptive analysis using SPSS v26.0 was conducted to determine the frequency, mean and standard deviation of the study variables (IGEN, IPROM, IIMPL, HUM, TW) to investigate the respondents' perception of each variable. The level of the respondents' adoption of IB in this study was measured through three constructs based on the second-order model of innovative behavior developed by Amir (2015), which are idea generation (IGEN), idea promotion (IPROM), and idea implementation (IIMPL). The data were provided by the items under Part B in the survey instrument. The results of the descriptive analysis for all the variables investigated in this study are summarized in Table 2. 
Table 2. Summary of Descriptive Analysis

\begin{tabular}{lcll}
\hline & Item & Mean & SD \\
\hline 1 & IGEN & 4.032 & 0.564 \\
2 & IPROM & 3.853 & 0.602 \\
3 & IIMPL & 3.662 & 0.636 \\
4 & HUM & 3.939 & 0.676 \\
5 & TW & 3.974 & 0.559 \\
\hline
\end{tabular}

Note. Idea generation =IGEN, idea promotion IPROM, idea implementation $=$ IIMPL, humor=HUM, teamwork $=\mathrm{TW}$.

As shown in Table 1.3, IIMPL has the lowest score (mean $=3.662)$. This indicates that the majority of the respondents had the lowest level of engagement in implementing their ideas until the ideas were accepted and adopted by users. The score for IPROM was moderate (mean $=3.853$ ), indicating that the respondents only had a moderate level of engagement in championing their new ideas and gaining support from other teachers or supervisors at the idea promotion stage. Meanwhile, the highest score for IGEN (mean $=4.032)$ indicates that most respondents had a good level of engagement in generating new ideas, exploring new ways to do things, or solving problems to improve the school performance and enhance students' learning.

The respondents' perceptions of HUM (mean HUM = 3.939, s.d = 0.676), and TW (mean = 3.974 , s.d $=0.559$ ) are fairly good.

A correlation analysis was carried out to determine the degree of association among IB (IGEN, IPROM, IIMPL), HUM, and TW, and to determine the linearity of the relationship. The overall mean scores for HUM were tabulated against the overall mean scores for IGEN, IPROM, and IIMPL. The results in Table 1.4 showcase positive correlations between IB constructs (IGEN, IPROM, and IIMPL) with HUM. The results of the correlation analysis are summarized in Table 3.

Table 3. Correlation Analysis Result

\begin{tabular}{lllcccc}
\hline & & & 1 & 2 & 3 & 4 \\
\hline 1. & HU & Pearson Correlation & 1 & $\mathbf{. 4 2 5 * *}$ & $\mathbf{. 4 6 1}$ & $\mathbf{. 4 1 7 ^ { * * * }}$ \\
& $\mathrm{M}$ & Sig. (1-tailed) & & $\mathbf{. 0 0 0}$ & $\mathbf{. 0 0 0}$ & $\mathbf{. 0 0 0}$ \\
& & $\mathrm{N}$ & 354 & 354 & 354 & 354 \\
\hline 2. & IGE & Pearson Correlation & $.425^{* *}$ & 1 & $.546^{* *}$ & $.514^{* *}$ \\
& $\mathrm{~N}$ & Sig. (1-tailed) & .000 & & .000 & .000 \\
& & $\mathrm{~N}$ & 354 & 354 & 354 & 354 \\
\hline 3 & IPR & Pearson Correlation & $.461^{* *}$ & $.546^{* *}$ & 1 & $.635^{* *}$ \\
& OM & Sig. (1-tailed) & .000 & .000 & & .000 \\
& & $\mathrm{~N}$ & 354 & 354 & 354 & 354 \\
\hline 4. & IIM & Pearson Correlation & $.417^{* *}$ & $.514^{* *}$ & $.635^{* *}$ & 1 \\
& PL & Sig. (1-tailed) & .000 & .000 & .000 & \\
& & $\mathrm{~N}$ & 354 & 354 & 354 & 354 \\
\hline
\end{tabular}


Note. Idea generation $=\mathrm{IGEN}$, idea promotion IPROM, idea implementation =IIMPL, humor=HUM, teamwork $=$ TW. **. Correlation is significant at the 0.01 level (1-tailed).

The overall mean scores for TW were tabulated against the overall mean scores for IGEN, IPROM, and IIMPL. The results of the correlation analysis are summarized in Table 1.5, which indicates that all constructs under the IB variable (IGEN, IPROM, and IIMPL) are strongly correlated with TW.

Table 4. Correlation Analysis Results

\begin{tabular}{lllcccc}
\hline & & & 1 & 2 & 3 & 4 \\
\hline 1. & TW & Pearson Correlation & 1 &. $\mathbf{4 7 0 * *}$ & $\mathbf{. 5 2 0 *}$ & $\mathbf{. 4 7 2 * *}$ \\
& & Sig. (1-tailed) & & $\mathbf{. 0 0 0}$ & $\mathbf{. 0 0 0}$ & $\mathbf{. 0 0 0}$ \\
& & $\mathrm{N}$ & 354 & 354 & 354 & 354 \\
\hline 2. & IGE & Pearson Correlation & $.470^{* *}$ & 1 & $.546^{* *}$ & $.514^{* * *}$ \\
& $\mathrm{~N}$ & Sig. (1-tailed) & .000 & & .000 & .000 \\
& & $\mathrm{~N}$ & 354 & 354 & 354 & 354 \\
\hline 3. & IPR & Pearson Correlation & $.520^{* *}$ & $.546^{* *}$ & 1 & $.635^{* *}$ \\
& OM & Sig. (1-tailed) & .000 & .000 & & .000 \\
& & $\mathrm{~N}$ & 354 & 354 & 354 & 354 \\
\hline 4. & IIMP & Pearson Correlation & $.472^{* *}$ & $.514^{* *}$ & $.635^{* *}$ & 1 \\
& L & Sig. (1-tailed) & .000 & .000 & .000 & \\
& & $\mathrm{~N}$ & 354 & 354 & 354 & 354 \\
\hline
\end{tabular}

Note. Idea generation =IGEN, idea promotion IPROM, idea implementation =IIMPL, humor=HUM, teamwork $=$ TW. $* *$. Correlation is significant at the 0.01 level $(1$-tailed). $* *$ Correlation is significant at the 0.01 level (1-tailed)

Based on the descriptive analysis results, the majority of the teachers reported a good level of adoption of the IGEN behavior. Previous studies have shown that developing the IGEN behavior is important because innovation only begins when a person can recognize a problem and generate ideas or solutions to the problem, either novel or adopted (Kanter, 1988). Therefore, teachers need to adopt good IGEN behavior to initiate the innovation process. They must know how to identify problems and learn to generate ideas to solve the identified problems. They must also be able to combine and reorganize information gained from IGEN activities, such as reflection, observation, conversation, and communication, and integrate the information with their knowledge and experience to improve teaching and learning performance. Besides that, teachers must be competent in approaching problems or performance gaps from a different angle.

Idea promotion in this study refers to the teachers' behavior in gaining support from their colleagues and school leaders to guarantee the progress of the generated ideas (Janssen, 2005; Kanter, 1988b). The findings in this study show that the majority of the teachers reported a moderate level of engagement in the IPROM behavior. Previous studies have shown that it is important for teachers to develop good IPROM behavior because it would help them gain support from potential allies like colleagues, school leaders, or administrators in realizing 
their new ideas in the innovation process. Therefore, teachers need to have good skills and the ability to carry out activities at the IPROM stage. To convince the allies, teachers should formulate clear goals so that their allies could understand the necessity and usefulness of the innovation.

Idea implementation in this study refers to the teachers' behavior in experimenting and implementing the new ideas until they are adopted by relevant parties (Choi \& Chang, 2009). The findings in this study show that many of the teachers reported a moderate level of engagement in the IIMPL behavior. Previous studies have shown that it is important for teachers to have a good strategy for an idea implementation because it is a crucial component of successful innovations (Messmann \& Mulder, 2011). Therefore, considerable effort and a results-oriented attitude are needed from the teachers for successful idea implementation. The teachers should also know how and when to modify the ideas during the IIMPL stage if the situations are different from what was initially expected. Considering the change of situations, teachers may need to go through an idea generation and idea promotion stage again but using a different approach. This usually happens when the ideas are not easily adopted or when there are new parties that must be convinced. Other than that, the teachers should create transparency so that people who contribute to the IIMPL process can monitor the progress and see the results.

The use of amusing anecdotes and jokes by teachers to cause laughter and amusement when interacting with their students in the classroom to create a more pleasant, fun, and exciting environment that increases learning is referred to as pedagogical humor in this study. Teachers' pedagogical humor may involve the use of amusing props, puns, short stories, anecdotes, riddles, or cartoons, in addition to jokes or humorous stories (Weimer, 2013). The results suggest that most teachers were in favor of incorporating humor into their teaching methods. Previous research has demonstrated that pedagogical humor can help to create a more pleasant, entertaining, and fascinating learning environment for students. When used appropriately, constructively, and in moderation, pedagogical humor can facilitate the comprehension and retention of learned material (Glenn, 2002). As a result, it is recommended that teachers incorporate suitable humor into their teaching strategies to aid students' learning. Jokes or hilarious stories should be planned and practiced, as well as how the class will react to them. Teachers should also be aware of subjects or topics that are likely to arouse strong emotions, such as death or harm to others, especially animals, and should refrain from using humor that involves legally protected personal traits (for example, color, religion, disabilities, national origin, age, and gender) (Roslan et al., 2021).

In this study, teamwork (TW) refers to teachers' perceptions of their teacher's group's collaboration in creating a positive and cooperative environment at their school through effective communication, support and caring relationships, and knowledge and skill sharing to contribute to organizational success (Ladd \& Henry, 2000). The majority of teachers had good opinions of the level of collaboration displayed by their colleagues at the school in working together to promote the school's success and kids' academic performance, according to the findings of this survey. Previous research has demonstrated that effective teamwork is vital because it improves team members' concentration on a single objective and a clear 
purpose, which is critical for organizational success (e.g., Katzenbach \& Smith, 2015). To establish and nurture a healthy and successful work environment in schools, instructors must have a high degree of collaboration in which all teachers are willing to contribute and participate. Teachers must be adaptable enough to work in cooperative settings where goals are achieved through collaboration and social interdependence rather than competition.

As discussed earlier, the relationship between the humor factor and teachers' innovative behavior has been understudied as concluded from the literature. Little has been done to investigate how teachers' humor can stimulate their innovative behavior in teaching and learning practices. Therefore, a correlation analysis was carried out in this study to understand the significance of humor in the development of teachers' innovative behavior in terms of idea generation (IGEN), idea promotion (IPROM), and idea implementation (IIMPL). The findings reveal that there is enough data to show that respondents' perceptions of their pedagogical humor use have a favorable and significant impact on their idea development, idea promotion, and idea implementation behavior. These findings support prior research that suggests that people who use a sense of humor at work can improve the organization's innovation and outcomes (Romero \& Cruthirds, 2006). Those who have high humor traits, do not take themselves too seriously although they might be focused and passionate about their pursuits. These traits would help them to convince their colleagues and school leaders to support their seemingly impossible ideas using pure logic. This would also help the teachers to overcome creative blocks and manage criticisms.

Although many past studies have investigated the impact of teamwork on innovative behavior, little has been done to examine the teamwork factor on teachers' innovative behavior within the context of Malaysian schools. The correlation analysis results show that there is sufficient evidence to prove that the respondents' perceptions towards teamwork among teachers at their schools have a positive and significant influence on their idea generation behavior, idea promotion behavior, and idea implementation behavior. Therefore, it can be concluded that the teamwork factor significantly and positively contributes to all three constructs in innovative behavior. These findings are in line with earlier research showing that teamwork is linked to innovative behavior. Increased communication in a cooperative environment and networking among coworkers, according to Horng et al. (2005), may boost the creation of innovative ideas. Employees can exchange and discuss new ideas and practices as part of a team to solve and even discover challenges. Their mutual encouragement motivates them to see these issues as opportunities to capitalize on. They share ideas and suggestions that provide them with a new viewpoint, the capacity to work together to overcome frustration, and the chance to integrate ideas in novel and successful ways. They collaborate on data collection to find the optimal answer and challenge the concept from several angles. This will enhance their confidence to see the idea through. Through teamwork, they can get other people to support the innovation process and gain the commitment of those who will be involved at the idea implementation stage. A positive working environment is also conducive for innovation, thus motivates an individual's innovative behavior (Scott \& Bruce, 1994).

Hence, it can be concluded that the teachers who participated in this study had demonstrated a good level of innovative behavior. This indicates that they had a positive attitude towards 
innovations and possess a desire, readiness, and ability to implement innovative teaching. They had exhibited the capability to choose the right type of activity in the innovation process, understand their role at each innovation stage, and develop goals and means to implement their ideas. The findings of this study also suggest that teachers were on pace to keep up with the rapidly changing educational system, which includes more diverse student populations, expanded knowledge disciplines, increased responsibilities, and higher societal expectations.

However, the finding of this study also shows that some of the teachers were not very good at developing new ideas based on their original thinking. Their ideas were mostly adapted from external sources, such as communicating and sharing information with colleagues or school leaders, observing how things are done by other teachers, conversing with students, and training. Therefore, it is recommended for the teachers to improve their creativity level and innovativeness to come up with more novel ideas. This can be done by developing specific competencies, such as ICT skills, analytic skills, and problem-solving skills as well as improve their cognitive abilities through education and experience so that they can do abstract reasoning, memory, and processing of novel information.

In short, this study has provided evidence that the teachers who participated in the study had demonstrated a good level of engagement in innovative behavior and were on the right path to adopt innovations within the context of Malaysian secondary schools. Consequently, teachers should be encouraged to utilize their humor traits in generating innovative ideas, to build an innovative culture within schools through good teamwork and adopt more effective and innovative forms of teaching for better students' learning and engagement.

The outcome of this study can be used as a reference by Malaysian teachers to understand the importance of innovative behaviors in helping them to keep up with the rapid changes in the educational system and school curriculum, increased student populations, expanding knowledge fields, new responsibilities, advanced technologies, and higher social expectations. This study should also provide teachers with a better insight into how the humor factor, teamwork factor, and perceived supervisor support may contribute to the development of their innovative behaviors. This will enable them to successfully implement innovations in teaching and learning to improve student's learning and engagement in the classroom and, as a result, meet the expectations of $21^{\text {st }}$ century learning.

Given the positive influence of humor traits on innovative behavior, teachers should be encouraged to integrate humor in teaching by using jokes, funny stories, props, riddles, and cartoons to stimulate their innovative behaviors. Teachers should also be encouraged to collaborate on collaborative projects, particularly with colleagues who are subject-matter experts in different subjects, exchanging ideas and methodologies on a more frequent basis than with colleagues in their departments.

\section{References}

Aboudan, R. (2009). Laugh and learn: Humor and learning a second language. International Journal of Arts and Sciences, 3(3), 90-99. 


\section{Macrothink}

International Journal of Human Resource Studies

ISSN 2162-3058

2021, Vol. 11, No. 4S

Ahrari, S., Othman, J., \& Hassan, M. (2013). Role of Social Studies for Pre-Service Teachers in Citizenship Education. International Education Studies, 6(12), 1-8. https://doi.org/10.5539/ies.v6n12p1

Amir, M. T. (2015). Entrepreneurial behavior and innovative behavior: A conceptual clarification. The Asian Journal of Technology Management, 8(02), 161-72.

Askildson, L. (2005). Effects of humor in the language classroom: Humor as a pedagogical tool in theory and practice. Journal of Second Language Acquisition and Teaching, 12, 45-61.

Balkar, B. (2015). The relationships between organizational climate, innovative behavior and job performance of teachers. International Online Journal of Educational Sciences, 7(2), 81-92.

Bandura, A. (1977). Social Learning Theory. Prentice.

Binnewies, C., \& Gromer, M. (2012). Creativity and innovation at work: The role of work characteristics and personal initiative. Psicothema, 24(1), 100-105.

Bransford, J., Derry, S., Berliner, D., Hammerness, K., \& Beckett, K. L. (2005). Theories of learning and their roles in teaching. In L. Darling-Hammond \& J. Bransford (Eds.), Preparing teachers for a changing world: What teachers should learn and be able to do (pp. 40-87). Jossey-Bass.

Choi, J. N., \& Chang, J. Y. (2009). Innovation implementation in the public sector: An integration of institutional and collective dynamics. Journal of Applied Psychology, 94(1), 245-253.

Deviney, D. E., Crawford, J., \& Elder, K. L. (2013). Classroom antics: Fun with a purpose. Journal of Instructional Pedagogies, 10(1), 1-6.

Evers, A. T., Kreijns, K., Van der Heijden, B. I., \& Gerrichhauzen, J. T. (2011). An organizational and task perspective model aimed at enhancing teachers' professional development and occupational expertise. Human Resource Development Review, 10(2), 151-179.

Garba, S. A., Byabazaire, Y., \& Busthami, A. H. (2015). Toward the Use of 21 st Century Teaching-Learning Approaches: The Trend of Development in Malaysian Schools within the Context of Asia Pacific. International Journal of Emerging Technologies in Learning, 10(4), $72-79$

Glenn, R. (2002). Brain research: Practical applications for the classroom. Teaching for Excellence, 21(6), 1-2.

Horng, J.-S., Hong, J.-C., ChanLin, L.-J., \& Chu, H.-C. (2005). Creative teachers and creative teaching strategies. International Journal of Consumer Studies, 29, 352-358. https://doi.org/10.1111/j.1470-6431.2005.00445.x

Janssen, O. (2000). Job demands, perceptions of effort-reward fairness and innovative work behaviour. Journal of Occupational and Organizational Psychology, 73(3), 287-302. 
https://doi.org/10.1348/096317900167038

Janssen, O. (2003). Innovative behaviour and job involvement at the price of conflict and less satisfactory relations with co-workers. Journal of Occupational and Organizational Psychology, 76(3), 347-364.

Johari, A., Wahat, N. W. A., \& Zaremohzzabieh, Z. (2021). Innovative Work Behavior among Teachers in Malaysia: The Effects of Teamwork, Principal Support, and Humor. Asian Journal of University Education, 17(2), 72-84.

Katzenbach, J. R., \& Smith, D. K. (2015). The wisdom of teams: Creating the high-performance organization. Harvard Business Review Press.

Kleysen, R. F., \& Street, C. T. (2001). Toward a multi-dimensional measure of individual innovative behavior. Journal of Intellectual Capital, 2(3), 284-296.

Konermann, J. (2012). Teachers'work engagement: A deeper understanding of the role of job and personal resources in relationship to work engagement, its antecedents, and its outcomes [PhD Thesis]. University of Twente.

Ladd, D., \& Henry, R. A. (2000). Helping Coworkers and Helping the Organization: The Role of Support Perceptions, Exchange Ideology, and Conscientiousness. Journal of Applied Social Psychology, 30(10), 2028-2049.

Liou, Y.-H., Canrinus, E. T., \& Daly, A. J. (2019). Activating the implementers: The role of organizational expectations, teacher beliefs, and motivation in bringing about reform. Teaching and Teacher Education, 79, 60-72.

Martin, R. A., \& Ford, T. (2018). The psychology of humor: An integrative approach (2nd ed.). Academic press.

Messmann, G., \& Mulder, R. H. (2011). Innovative work behaviour in vocational colleges: Understanding how and why innovations are developed. Vocations and Learning, 4(1), 63-84. https://doi.org/10.1007/s12186-010-9049-y

Messmann, G., Mulder, R. H., \& Palonen, T. (2018). Vocational education teachers' personal network at school as a resource for innovative work behaviour. Journal of Workplace Learning, 30(3), 174-185. https://doi.org/10.1108/JWL-08-2017-0069

Meyer, K. (2014). Making meaning in mathematics problem solving using the reciprocal teaching approach. Literacy Learning: The Middle Years, 22(2), 7-14.

Mirkov, S. (2018). Teamwork for innovation in pharmacy practice: From traditional to flexible teams. Drugs \& Therapy Perspectives, 34(6), 274-280.

Nguyen, H. (2014). The use of humor in EFL teaching: A case study of Vietnamese university teachers' and students' perceptions and practices [Postgraduate Thesis]. University of Canberra.

Noon, E. J. (2017). An interpretative phenomenological analysis of the barriers to the use of 


\section{Macrothink}

International Journal of Human Resource Studies

ISSN 2162-3058

2021, Vol. 11, No. 4S

humour in the teaching of childhood studies. J Perspect Appl Acad Pract, 5(3), 45-52.

Ogbonnaya, C., Tillman, C. J., \& Gonzalez, K. (2018). Perceived organizational support in health care: The importance of teamwork and training for employee well-being and patient satisfaction. Group \& Organization Management, 43(3), 475-503.

Randi, J., \& Corno, L. (1997). Teachers as innovators. In B. J. Biddle, T. L. Good, \& I. F. Goodson (Eds.), International handbook of teachers and teaching: Vol. II (pp. 1163-1221). Kluwer.

Rogers, E. M. (1995). Diffusion of Innovations (4th ed.). Free Press.

Romero, E. J., \& Cruthirds, K. W. (2006). The use of humor in the workplace. Academy of Management Perspectives, 20(2), 58-69.

Roslan, S., Hasan, S., Zaremohzzabieh, Z., \& Arsad, N. M. (2021). Big Five Personality Traits as Predictors of Systems Thinking Ability of Upper Secondary School Students. Social Sciences and Humanities, 29(S1), 1-20.

Rusdin, N. M. (2018). Teachers' readiness in implementing 21st century learning. International Journal of Academic Research in Business and Social Sciences, 8(4), 1293-1306.

Scarnati, J. T. (2001). On becoming a team player. Team Performance Management: An International Journal, 7(1/2), 5-10.

Scott, S. G., \& Bruce, R. A. (1994). Determinants of innovative behavior: A path model of individual innovation in the workplace. Academy of Management Journal, 37(3), 580-607.

Serdyukov, P. (2017). Innovation in education: What works, what doesn't, and what to do about it? Journal of Research in Innovative Teaching \& Learning, 10(1), 4-33.

Stevenson, M., Bower, M., Falloon, G., Forbes, A., \& Hatzigianni, M. (2019). By design: Professional learning ecologies to develop primary school teachers' makerspaces pedagogical capabilities. British Journal of Educational Technology, 50(3), 1260-1274.

Sumardi, L., Rohman, A., \& Wahyudiati, D. (2020). Does the Teaching and Learning Process in Primary Schools Correspond to the Characteristics of the 21st Century Learning?. International Journal of Instruction, 13(3), 357-370.

Tarricone, P., \& Luca, J. (2002). Successful teamwork: A case study. 25th HERDSA Annual Conference, Perth, Western Australia.

Thurlings, M., Evers, A. T., \& Vermeulen, M. (2015). Toward a model of explaining teachers' innovative behavior: A literature review. Review of Educational Research, 85(3), 430-471. https://doi.org/10.3102/0034654314557949

Trapitsyn, S. Y., Granichin, O., Granichina, O. A., \& Zharova, M. V. (2018). Innovative behavior of teachers: Definition and analysis. 350-359.

Vrticka, P., Black, J. M., \& Reiss, A. L. (2013). The neural basis of humour processing. Nature 


\section{Macrothink}

International Journal of Human Resource Studies

ISSN 2162-3058 2021, Vol. 11, No. 4S

Reviews Neuroscience, 14(12), 860-868.

Warren, C., Barsky, A., \& McGraw, A. P. (2018). Humor, comedy, and consumer behavior. Journal of Consumer Research, 45(3), 529-552.

Weimer, M. (2013). Humor in the classroom: 40 years of research. The Teaching Professor, 25(10), 3-15.

Xerri, M., \& Brunetto, Y. (2011). Fostering the innovative behaviour of SME employees: A social capital perspective. Research and Practice in Human Resource Management, 19(2), 43-59.

Yu, Y., Shafto, P., Bonawitz, E., Yang, S. C.-H., Golinkoff, R. M., Corriveau, K. H., Hirsh-Pasek, K., \& Xu, F. (2018). The theoretical and methodological opportunities afforded by guided play with young children. Frontiers in Psychology, 9, 1-8.

\section{Copyright Disclaimer}

Copyright for this article is retained by the author(s), with first publication rights granted to the journal.

This is an open-access article distributed under the terms and conditions of the Creative Commons Attribution license (http://creativecommons.org/licenses/by/4.0/). 